\title{
Proposta de padronização para não conformidades aplicadas à fiscalização de sistemas de abastecimento de água por agências reguladoras
}

\author{
Standard proposal of nonconformities applied to inspection \\ of water supply systems by regulatory agencies
}

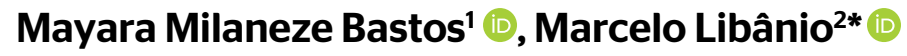

\section{RESUMO}

O presente estudo teve como objetivo propor uma padronização de não conformidades aplicadas à fiscalização direta de sistemas de abastecimento de água, com base nos instrumentos normativos do setor de saneamento e na experiência de agências reguladoras de âmbito nacional. Elaborou-se uma lista de itens para fiscalização fundamentada na análise de checklist e resoluções normativas disponíveis nos sítios eletrônicos de três agências reguladoras. A listagem compreendeu todas as unidades do sistema e os aspectos referentes à qualidade da água. Os 179 itens abordados foram enquadrados em: não conformidades (80); sujeitos à recomendação da agência (56); e de caráter informativo (43). Essa proposta visa ao aprimoramento dos instrumentos de fiscalização e da atividade regulatória, visto que um dos objetivos da regulação é o estabelecimento de padrões e normas à adequada prestação dos serviços e à satisfação dos usuários. Adicionalmente, a padronização das não conformidades permitirá comparações mais fidedignas entre sistemas de abastecimento, favorecendo a avaliação do desempenho dos prestadores e a melhoria contínua dos serviços.

Palavras-chave: não conformidade; padronização; fiscalização; abastecimento de água; regulação.

\section{ABSTRACT}

This study proposes a standardization of nonconformities applied to direct inspection of water supply systems using legal instruments of sanitation sector and national regulatory agencies' experience. From the analysis of checklist and normative resolutions available in three regulatory agencies websites - ARCE, ARSI and ARES-PC J - and of regulatory provisions related to sanitation, a list of items to check supply systems in direct inspection was made. The list includes all system units, from the water catchment areas to distribution network, besides the aspects of water quality. The items discussed were classified as: non-conformities; subject to the agency's recommendation and; for informational purposes only. The final document provides a list of 179 items for water supply systems' inspection, being 80 nonconformities, 56 items subject to the agency's recommendation and 43 items for information purposes only. This proposal is notable for the perspective of improvement supervisory tools and regulatory activity, since one of the regulation's objectives is to establish standards and norms for the adequate provision of services and customer satisfaction. In addition, the standardization of nonconformities allows for a better comparison between water supply systems from the weaknesses identified by the inspections to enable performance evaluation of service providers and encourage continuous improvement of public services. Keywords: nonconformity; standardization; inspection; water supply; regulation.

\section{INTRODUÇÃO E RELEVÂNCIA}

A despeito de esforços nas últimas décadas, as melhorias no setor de saneamento no Brasil avançam de maneira vagarosa, principalmente no que se refere à coleta e ao tratamento de esgoto doméstico, como indicam os dados de 2014 do Sistema Nacional de Informações sobre Saneamento (SNIS). A última pesquisa divulgada em 2016 apontou que a média nacional de coleta de esgotos em áreas urbanas é de 57,6\%, o

índice de tratamento dos esgotos gerados chega a 40,8\% e o dos esgotos coletados, a 70,9\% (BRASIL, 2016).

Diante desse cenário, priorizar políticas públicas relacionadas ao setor e planejar ações que conduzam à universalização do acesso ao saneamento básico e à estruturação do setor são atitudes fundamentais para o país. Uma iniciativa que coopera para o aprimoramento da prestação de serviços públicos de saneamento é a Lei Federal 
$\mathrm{n}^{\circ}$ 11.445/2007, denominada Lei Nacional do Saneamento Básico, que institui as diretrizes nacionais para o setor, bem como introduz sua regulação (BRASIL, 2007).

O Decreto $n^{\circ} 7.217 / 2010$, que estabelece as normas para execução da Lei Nacional do Saneamento, define regular como sendo o ato que discipline ou organize determinado serviço público, abrangendo suas características, padrões de qualidade, impacto socioambiental, direitos e deveres dos usuários e do prestador de serviços, além da definição e revisão de tarifas (BRASIL, 2010).

Conforme Galvão Junior (2006), o papel da regulação é assegurar que todos os serviços públicos sejam prestados de maneira adequada, ou seja, que atendam aos princípios básicos de regularidade, continuidade, eficiência, segurança, atualidade, generalidade, cortesia e modicidade, itens também destacados no art. $2^{\circ}$ da Lei $\mathrm{n}^{\circ} 11.445 / 2007$. Adicionalmente, a agência reguladora deve atuar para garantir o equilíbrio entre usuários, prestador de serviços e poder concedente.

Ainda de acordo com Galvão Junior (2006), a atividade regulatória é operacionalizada pelo ato de fiscalizar os serviços prestados, momento no qual será verificado o cumprimento do disposto em leis, decretos, normas relacionadas à atividade, bem como em resoluções editadas pelo ente regulador e em contrato de programa ou de concessão. Como produto, além dos documentos referentes aos procedimentos administrativos, tem-se o relatório de fiscalização, que inclui análises de dados e documentos recebidos do prestador de serviços, informações levantadas durante a inspeção de campo, não conformidades identificadas pelo fiscal, além de determinações e recomendações da agência reguladora.

O relatório de fiscalização é, portanto, um instrumento utilizado para registrar as constatações e conclusões da agência reguladora acerca da eficiência e qualidade do serviço prestado. Sendo assim, no que se refere à fiscalização de sistemas de abastecimento de água (SAAs) e de esgotamento sanitário (SESs), é importante que o relatório tenha caráter investigativo e abarque as condições operacionais e de manutenção do sistema fiscalizado, além das questões relativas ao atendimento ao usuário que não estejam de acordo com a normatização pertinente e com o contrato estabelecido entre o prestador de serviços e o poder concedente.

Considerando que não há um padrão estabelecido entre agências reguladoras no que se refere às constatações de deficiências nos sistemas fiscalizados, este trabalho teve como objetivo principal a proposição de padronização de não conformidades aplicadas à fiscalização de SAAs com base nos instrumentos legais que norteiam o setor e na experiência de três agências reguladoras nacionais.

Esta análise destaca-se pelo ponto de vista de aprimoramento dos instrumentos de fiscalização e da atividade regulatória. Além de contribuir para o aperfeiçoamento da ação de fiscalização, a padronização das não conformidades entre as agências permite comparação mais fidedigna de sistemas de saneamento a partir das deficiências identificadas, de forma a possibilitar avaliação do desempenho das entidades e incentivar a melhoria dos serviços prestados.

Adicionalmente, a ausência de uniformidade na própria agência reguladora quanto às não conformidades identificadas em fiscalizações dificulta o acompanhamento das correções realizadas no sistema e, por consequência, prejudica a qualidade dos serviços prestados e o usuário. Além disso, irregularidades não abordadas no relatório de fiscalização podem afetar o andamento de todo o processo na agência, incluindo a análise dos técnicos, bem como demandas do Ministério Público e do poder concedente.

\section{METODOLOGIA}

\section{Considerações gerais}

Este estudo foi realizado com base em informações disponibilizadas nos sítios eletrônicos de três agências reguladoras de saneamento básico de âmbito nacional e no conteúdo de dispositivos normativos que disciplinam esses serviços. Para a proposição de padrão de não conformidades aplicadas à fiscalização realizadas por agências reguladoras foram definidas algumas condições:

- a fiscalização é de rotina, ou seja, programada pela agência reguladora, não sendo um atendimento à demanda específica;

- o objeto da fiscalização é o sistema de abastecimento de água;

- a fiscalização refere-se à área técnico-operacional, sendo avaliados pelos fiscais responsáveis equipamentos e instalações pertencentes às etapas do SAA (captação, adução, tratamento, reservação e distribuição), contemplando sua operação e manutenção, além de aspectos referentes ao manancial de abastecimento e à qualidade da água distribuída;

- o tratamento de água realizado na estação é do tipo convencional (coagulação, floculação, decantação, filtração e desinfecção);

- a fiscalização da área comercial do prestador de serviços e de questões referentes ao contrato estabelecido entre poder concedente e prestador de serviços não foram consideradas neste trabalho.

\section{Seleção das agências reguladoras}

Para este estudo foram selecionadas três agências reguladoras no universo das 53 associadas à Associação Brasileira de Agências Reguladoras (ABAR, 2015), sendo duas da esfera estadual e uma da municipal. Para escolha das agências duas condições consideradas:

- agências que atuem na regulação dos serviços de abastecimento de água;

- disponibilidade de informações no sítio eletrônico no que se refere à fiscalização e à regulação dos serviços de abastecimento de água. 
Tais informações contemplavam relatórios de fiscalização, documentos de apoio, como checklist, manual de fiscalização, publicações e resoluções editadas pela agência. Nesse contexto, as três agências reguladoras selecionadas foram:

- Agência Reguladora de Serviços Públicos Delegados do Estado do Ceará (ARCE, 2010a, 2010b);

- Agência Reguladora de Saneamento Básico e Infraestrutura Viária do Espírito Santo (ARSI, 2010, 2011, 2018). Após Lei Complementar $n^{\circ} 827$ de julho de 2016, passou a ser denominada de Agência de Regulação de Serviços Públicos (ARSP). Ressalta-se, entretanto, que as referências correlatas à ARSI foram coletadas em abril de 2016 (ESPÍRITO SANTO, 2016);

- Agência Reguladora dos Serviços de Saneamento das Bacias dos Rios Piracicaba, Capivari e Jundiaí (ARES-PCJ, 2014c, 2014d).

Salienta-se que a verificação de três agências que atendessem aos requisitos citados foi condição para cessar a busca de entidades para este estudo. Ressalta-se que a ARCE regula o serviço de abastecimento de água da Região Metropolitana de Fortaleza de acordo com dados divulgados em 2017 pelo Instituto Brasileiro de Geografia e Estatística (IBGE), o Estado do Ceará é o $8^{\circ}$ mais populoso do Brasil. Adicionalmente, a atual ARSP é responsável pela regulação do referido serviço na Região Metropolitana de
Vitória - o Estado do Espírito Santo é o $14^{\circ}$ mais populoso do Brasil, de acordo com o IBGE.

\section{Seleção da ferramenta documental das agências reguladoras}

Para cada uma das três agências reguladoras selecionadas, ARCE, ARSI e ARES-PCJ, foram coletados nos respectivos sítios eletrônicos os documentos disponíveis referentes à fiscalização e à regulação dos serviços de abastecimento de água, a fim de verificar as condições operacionais e de manutenção consideradas pelas agências em suas ações de fiscalização. O Quadro 1 apresenta as resoluções e os documentos de apoio considerados de interesse para este estudo.

No que se refere aos relatórios de fiscalização, apenas os da ARES-PCJ foram considerados neste trabalho, visto que apresentam uma espécie de checklist para diagnóstico do sistema fiscalizado. Como as agências ARCE e ARSI disponibilizam esse instrumento de forma separada, seus relatórios não foram analisados. Salienta-se que foram considerados dois relatórios da ARES-PCJ, de forma a garantir a abordagem da fiscalização em sistemas com captação superficial e subterrânea:

- Relatório de Fiscalização Técnica dos Sistemas de Água e Esgoto do Município de Araraquara (ARES-PCJ, 2014a), município de Araraquara;

Quadro 1- Resoluções e documentos de apoio inerentes às três agências reguladoras abarcadas pela pesquisa.

\begin{tabular}{|l|l|}
\hline Resolução ARCE no 130/10 \\
\hline Resolução ARCE no 147/10 \\
\hline $\begin{array}{l}\text { Publicação: Procedimento de Fiscalização } \\
\text { em Sistemas de Abastecimento de Água }\end{array}$ \\
\hline
\end{tabular}

\begin{tabular}{|l|}
\hline Resolução ARSI no 008/10 \\
\hline Checklist de Fiscalização \\
\hline $\begin{array}{l}\text { Manual de Fiscalização - Prestação dos Serviços de } \\
\text { Abastecimento de Agua e Esgotamento Sanitário }\end{array}$ \\
\hline
\end{tabular}

Resolução ARES-PCJ no 48/14

Resolução ARES-PCJ no 50/14
Resolução/Documento de Apoio

\section{Conteúdo}

ARCE

Estabelece as condições gerais na prestação e utilização dos serviços públicos de abastecimento de água e de esgotamento sanitário

Dispõe sobre as sanções administrativas aplicáveis à Companhia de Água e Esgoto do Ceará (Cagece), em razão de infrações aos direitos dos usuários, bem como os procedimentos de fiscalização e aplicação das penalidades, e dá outras providências

Aborda, entre outros itens, os procedimentos e as atividades de campo de uma agência reguladora, incluindo modelos de relatório de fiscalização e lista de verificação (checklist) ARSI

Estabelece as condições gerais para a prestação e utilização dos serviços públicos de abastecimento de água e de esgotamento sanitário

Formulário específico desenvolvido para aquisição de dados

Estabelece procedimentos padronizados para fiscalização e análise dos procedimentos de operação e manutenção dos serviços de abastecimento de água e esgotamento sanitário regulados pela ARSI

ARES-PCJ

Dispõe sobre a definição de não conformidades a serem verificadas na fiscalização da prestação dos serviços de água e esgoto, no âmbito dos municípios associados à Agência Reguladora PCJ

Estabelece as condições gerais de prestação dos serviços públicos de abastecimento de água tratada e de esgotamento sanitário, no âmbito dos municípios associados à Agência Reguladora PCJ

*O pioneirismo da ARCE na área de regulação possibilitou o desenvolvimento desta publicação, que apresenta uma metodologia específica de fiscalização dos serviços de água, cujos resultados, de acordo com a agência, são eficientes e contribuíram para a melhoria dos serviços prestados pela concessionária aos usuários; ARCE: Agência Reguladora de Serviços Públicos Delegados do Estado do Ceará; ARSI: Agência Reguladora de Saneamento Básico e Infraestrutura Viária do Espírito Santo; ARES-PCJ: Agência Reguladora dos Serviços de Saneamento das Bacias dos Rios Piracicaba, Capivari e Jundiaí.

Fonte: ARES-PCJ, 2014c; 2014d; AGÊNCIA REGULADORA DE SANEAMENTO BÁSICO E INFRAESTRUTURA VIÁRIA DO ESPÍRITO SANTO, 2016a; 2016b; 2O16c; 2016d; 2016e. 
- Relatório de Fiscalização Técnica dos Sistemas de Água e Esgoto do Município de Cerquilho (2014b), município de Cerquilho.

\section{Determinação de itens para fiscalização direta de sistemas de abastecimento de água}

Os itens a serem verificados na fiscalização de SAAs foram determinados a partir da seleção dos componentes em comum observados nos checklists disponibilizados nos sítios eletrônicos das agências ARSI e ARCE - este último consta no Apêndice 1 da publicação: Procedimento de Fiscalização em Sistemas de Abastecimento de Água, bem como no checklist apresentado no corpo do texto dos relatórios de fiscalização elaborado pela ARES-PCJ e utilizados neste trabalho.

Após essa seleção inicial de itens em comum às três agências foi realizada validação da lista de verificação obtida. Para isso, os checklists foram avaliados novamente e as resoluções emitidas pelas agências analisadas, a fim de verificar se itens relevantes do ponto de vista dos instrumentos normativos do setor de saneamento e dos aspectos considerados em resolução deixaram de ser considerados por não serem comuns às três entidades ou por não constarem nos mencionados checklists.

Em seguida, a listagem obtida foi revisada a fim de averiguar se ela abrangeu os itens considerados por Araújo et al. (2009), e que fazem referência às condições gerais que devem ser observadas na fiscalização direta de SAA (área técnico-operacional), tendo como cerne a segurança do abastecimento e a qualidade do serviço. Os itens contemplados foram preservação, proteção e identificação, conservação e limpeza, operação e manutenção, segurança, monitoramento da qualidade da água bruta e tratada, controle de perdas e destinação de resíduos.
Após as análises e revisões descritas foram realizadas adequações textuais em cada um dos itens considerados, visto que não há um padrão entre as agências. Na etapa de validação da listagem obtida, os instrumentos normativos considerados para avaliar a inclusão de item ao documento são os de âmbito nacional, incluindo leis federais, decretos e normas referentes ao setor de saneamento. Os instrumentos estaduais, que podem ser mais restritivos, também podem ser acatados pelas agências. Entretanto, neste trabalho, não foram considerados, pois não se trata de estudo voltado para uma região específica. As especificidades de cada região devem ser, portanto, avaliadas por cada ente regulador.

\section{Enquadramento de constatações aos instrumentos legais}

Após revisão da relação de itens para apuração da fiscalização e respectivas reformulações textuais, foram identificados aqueles que podem ser enquadrados como não conformidade, que, segundo Galvão Junior (2006, p. 17), caracteriza a constatação, fato inerente à prestação dos serviços, "como em desacordo com os dispositivos legais que regulamentam a concessão, não atende ao contrato de concessão ou mesmo desobedece à legislação do setor de saneamento". Neste trabalho foram consideradas leis nacionais e normas técnicas vigentes relacionadas ao setor de saneamento. No Quadro 2 são apresentados os dispositivos normativos identificados, a partir da análise realizada, para enquadramento das constatações.

Ressalta-se que itens em que a base legal nacional não foi identificada foram considerados sujeitos à recomendação da agência, consoante com Galvão Junior (2006). Os demais componentes da listagem, cujo

Quadro 2 - Instrumentos normativos identificados para enquadramento de constatações.

\begin{tabular}{|c|c|}
\hline Instrumento Normativo & Conteúdo \\
\hline Lei no 11.445/07 & Estabelece diretrizes para o saneamento básico \\
\hline Decreto 7.217/10 & Regulamenta a Lei no 11.445/07 \\
\hline Portaria do Ministério da Saúde no 2.914/11 & $\begin{array}{l}\text { Dispõe sobre os procedimentos de controle e de vigilância da qualidade da água para consumo } \\
\text { humano e seu padrão de potabilidade }\end{array}$ \\
\hline Decreto no 5.440/05 & $\begin{array}{c}\text { Estabelece definições e procedimentos sobre o controle de qualidade da água de sistemas de } \\
\text { abastecimento e institui mecanismos e instrumentos para divulgação de informação ao consumidor } \\
\text { sobre a qualidade da água para consumo humano }\end{array}$ \\
\hline Portaria no 635/GM/MS/76 & Aprova normas e padrões sobre a fluoretação da água, tendo em vista a Lei n 6.050/74 \\
\hline Lei no 6.938/81 & Política Nacional do Meio Ambiente \\
\hline Lei no 9.433/97 & Política Nacional dos Recursos Hídricos \\
\hline ABNT NBR 12214/92 & Projeto de sistema de bombeamento de água para abastecimento público \\
\hline ABNT NBR 12215/91 & Projeto de adutora de água para abastecimento público (NB 591) \\
\hline ABNT NBR 12216/92 & Projeto de estação de tratamento de água para abastecimento público \\
\hline ABNT NBR $12217 / 94$ & Projeto de reservatório de distribuição de água para abastecimento público \\
\hline ABNT NBR 12218/94 & Projeto de rede de distribuição de água para abastecimento público \\
\hline ABNT NBR 12244/92 & Construção de poço para captação de água subterrânea \\
\hline
\end{tabular}

Fonte: BRASIL, 1976; 1981; 1997; 2007; 2010; 2011; ABNT, 1991; 1992a; 1992b; 1992c; 1994a; 1994b. 
conteúdo apenas compõe os relatórios de fiscalização das agências e não se enquadra nos dispositivos legais ou nas recomendações, foram considerados como itens informativos.

\section{RESULTADOS E DISCUSSÃO}

O resultado final do estudo, apresentado no Apêndice 1, trata-se de uma relação de itens para fiscalização direta, que compreende todas as unidades do sistema de abastecimento de água, desde o manancial de captação até a rede de distribuição. A listagem inclui:

- não conformidades, possíveis irregularidades do sistema e respectivos instrumentos legais de referência;

- itens sujeitos à recomendação da agência, aspectos considerados relevantes do ponto de vista da qualidade da prestação de serviços, mas cujos dispositivos normativos não foram identificados; $\mathrm{e}$

- itens de caráter informativo, que têm o objetivo de compor o diagnóstico do sistema. O documento elaborado apresenta ainda a indicação de quais agências consideram os itens abordados, seja nos checklists utilizados ou nas resoluções consideradas neste estudo.

No total, o documento apresenta 179 itens para fiscalização direta de sistemas de abastecimento de água. A Figura 1 apresenta o quantitativo de itens caracterizados em informativo, sujeito à recomendação e não conformidade, além de indicar o número de agências que, do ponto de vista da análise documental realizada, verificam os itens nas fiscalizações de SAAs.
O enquadramento das possíveis irregularidades constatadas em campo nos dispositivos legais resultou em 80 não conformidades, das quais 75\% são abordadas por, pelo menos, duas agências. O Quadro 3 apresenta detalhamento do conteúdo dos instrumentos normativos identificados que determinam a classificação de componentes da lista como não conformidades.

Vale ressaltar que as não conformidades são irregularidades verificadas nas condições da prestação de serviços ou nos procedimentos realizados e que não estão de acordo com a legislação, com o contrato ou com as normas técnicas de saneamento básico, inclusive as expedidas pela própria agência reguladora. Neste estudo foram considerados apenas instrumentos normativos de âmbito nacional relacionados ao setor de saneamento, sendo importante destacar que as agências reguladoras e o próprio contrato, instituído entre poder concedente e prestador de serviços, podem estabelecer condições mais restritivas para a prestação do serviço.

A inclusão de oito itens, enquadrados como não conformidades, não abordados por nenhuma das três agências é justificada pelo fato de, sob a óptica deste trabalho, serem compreendidos como irregularidades relacionadas a uma prestação deficiente do ponto de vista de um desses aspectos: operação e segurança do sistema, e informação e controle da qualidade de água.

Salienta-se que as não conformidades: "Não cumprimento da publicidade das informações mínimas sobre a água para consumo humano entregue aos consumidores por meios alternativos de abastecimento" refere-se a situações de desabastecimento da população, em que é

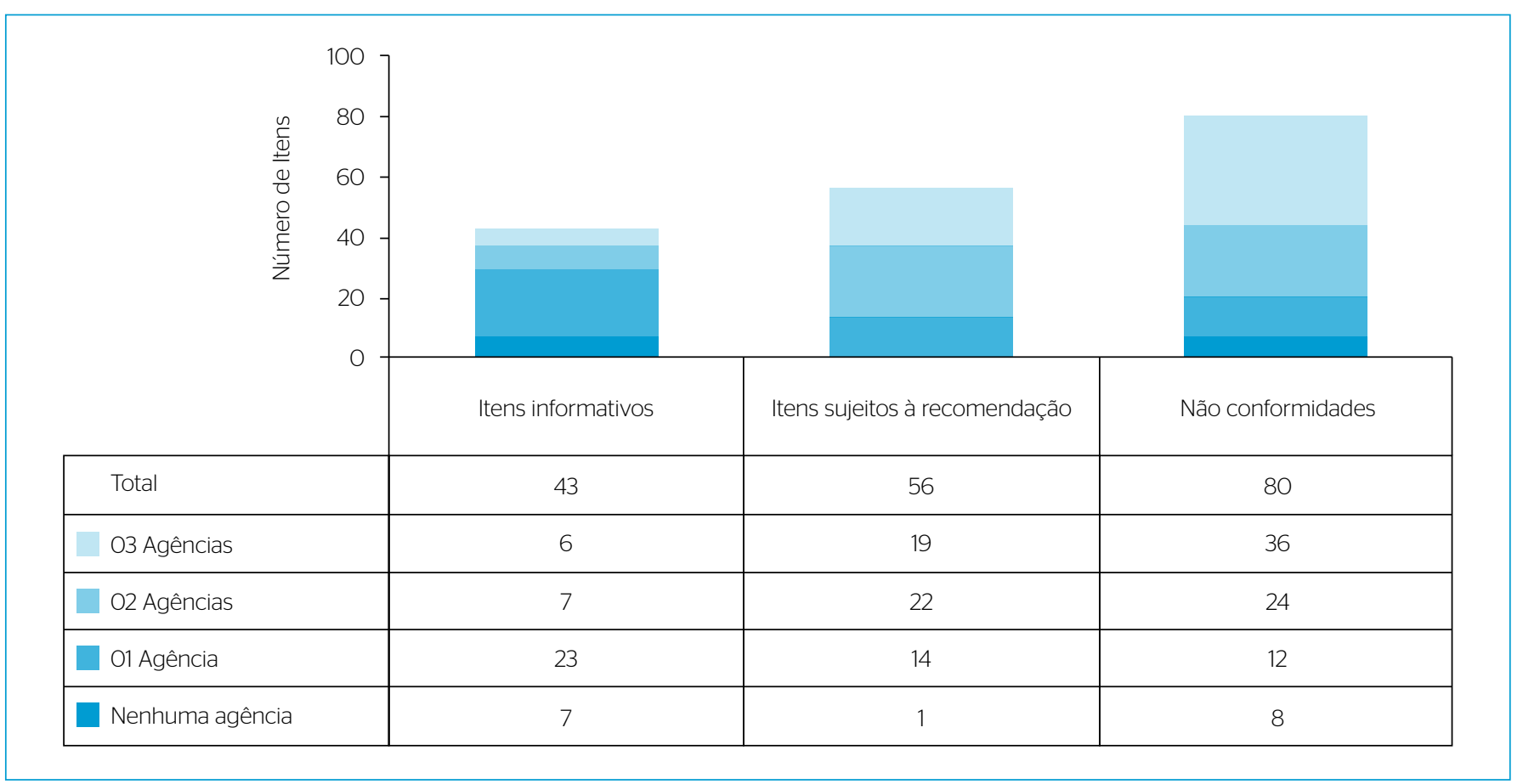

Figura 1 - Enquadramento dos itens para fiscalização direta de sistemas de abastecimento de água de acordo com a metodologia proposta. 
necessário abastecimento, por exemplo, por caminhão-pipa - e "Ausência ou não cumprimento do Plano de Emergência e Contingência” foram apresentadas à parte no Apêndice 1, visto que não se referem a uma unidade específica do SAA, mas cuja verificação é relevante em situações de anormalidade do sistema. O Plano de Emergência e Contingência (PEC) trata de situações de emergências de caráter natural ou operacional às quais o sistema está sujeito e deve incluir providências imediatas para comunicação à população, além de medidas para correção de irregularidades. A agência pode estabelecer seu conteúdo mínimo em resolução específica, sendo que o documento pode variar em função das peculiaridades de cada região.

Ressalta-se que nenhuma das três agências fez menção, na perspectiva considerada por este estudo, ao PEC, apesar de disporem em resolução sobre algumas medidas básicas a serem tomadas em situações de interrupção dos serviços, como orientações à população acerca dos procedimentos necessários e obrigação de comunicação aos usuários e à agência.

Itens considerados como sujeitos à recomendação da agência, total de 56, referem-se àqueles em que não foi identificado dispositivo normativo de referência, mas que ainda assim, sob o enfoque operacional, de limpeza e manutenção do sistema, da segurança da qualidade da água e do controle de perdas, podem ser aprimorados pelo prestador de serviços.

Com exceção do item frequência de inspeção sanitária, referente ao reservatório, todos foram abordados por, pelo menos, uma das agências. Optou-se por incluir esse componente, visto que as três entidades reguladoras apresentam a necessidade de limpeza e desinfecção dos reservatórios fiscalizados, não sendo clara, entretanto, a necessidade prévia de inspeção desses locais nos checklists e nas resoluções considerados. A análise periódica da água reservada é fundamental, pois permite verificar a presença de bactérias heterotróficas acima do preconizado pela Portaria no 2.914 (art. 28 $)$ (BRASIL, 2011), que recomenda que em caso de presença acima de $500 \mathrm{UFC} \cdot \mathrm{mL}^{-1}$ providências devem ser adotadas para o restabelecimento da integridade do sistema.

Apesar de os itens relacionados à ausência/vencimento de outorga - captação superficial ou subterrânea - e ao licenciamento ambiental da ETA estarem previstos nas Leis federais $\mathrm{n}^{\circ}$ 9.433/97 e $n^{\circ}$ 6.938/81 (BRASIL, 1981; 1997), respectivamente, eles não foram considerados como não conformidades, pois este trabalho tratou

Quadro 3 - Detalhamento do conteúdo dos instrumentos normativos considerados.

\begin{tabular}{|c|c|}
\hline Instrumento Normativo & Detalhamento do Conteúdo \\
\hline Lei Federal no 11.445/07 & $\begin{array}{c}\text { - Inciso V do Art. } 2^{\circ} \text { - princípio da adoção de métodos, técnicas e processos que considerem as } \\
\text { peculiaridades locais e regionais: Plano de Emergência e Contingência; } \\
\text { - Inciso XI do Art. } 2^{\circ} \text { - princípio da segurança: identificação das unidades operacionais e proteção da } \\
\text { área de captação (superficial e subterrânea) e de elevatórias; } \\
\text { - Inciso XI do Art. } 2^{\circ} \text { - princípio da qualidade: presença de vazamentos nas instalações da unidade } \\
\text { operacional, irregularidade que contribui para o volume de água perdido pelo sistema e, no caso de } \\
\text { reservatórios, para a contaminação da água reservada; } \\
\text { - §1० do Art. } 40^{\circ} \text { - comunicação prévia das interrupções programadas ao regulador e aos usuários. }\end{array}$ \\
\hline Decreto Federal no 7.217/10 & $\begin{array}{l}\text { - Art. } 17 \text { - princípio da continuidade da prestação dos serviços de saneamento: vazões (captação e } \\
\text { reservatório) não atendem à demanda da população e região sujeita à intermitência de abastecimento. }\end{array}$ \\
\hline Portaria do Ministério da Saúde n 2.914/11 & $\begin{array}{c}\text { - Descumprir ou não monitorar o parâmetro turbidez na saída do filtro; } \\
\text { - Descumprir ou não monitorar os padrões de potabilidade na saída da ETA e no sistema de distribuiçãa; } \\
\text { - Descumprir o Plano de Amostragem; } \\
\text { - Inciso IV do Art. } 130 \text { - avaliação sistemática do SAA, sob a perspectiva dos riscos à saúde, } \\
\text { considerando a ocupação da bacia contribuinte ao manancial: inspeções sanitárias na área de entorno } \\
\text { do manancial para averiguar possíveis fontes poluidoras; } \\
\text { - §30 do Art. } 280 \text { - recomendação de limite máximo para concentração de bactérias heterotróficas } \\
\text { e adoção de providências se identificada irregularidade: questão considerada para a unidade de } \\
\text { reservação a fim de identificar necessidade de limpeza e desinfecção. }\end{array}$ \\
\hline Decreto Federal no 5.440/05 & $\begin{array}{l}\text { - Inciso I do Art. } 5^{0} \text { - publicidade das informações acerca da qualidade da água nas faturas mensais; } \\
\text { - Art. } 9^{0} \text { - informações mínimas no caso de fornecimento de água potável por meio alternativo pelo } \\
\text { prestador de serviços. }\end{array}$ \\
\hline Portaria no 635/GM/MS/76 & - Limites recomendados para concentração de flúor na água tratada. \\
\hline ABNT NBR & $\begin{array}{c}\text { - Condições de segurança para os operadores; } \\
\text { - Condições de segurança da ETA e dos reservatórios; } \\
\text { - Condições de segurança da água; } \\
\text { - Condições de garantia do abastecimento contínuo; } \\
\text { - Condições de operação e manutenção de equipamentos e unidades; } \\
\text { - Controle de vazão; } \\
\text { - Controle de resíduos. }\end{array}$ \\
\hline
\end{tabular}

ETA: estação de tratamento de água; SAA: sistema de abastecimento de água.

Fonte: BRASIL (1976; 2005; 2007; 2010; 2011). 
aspectos previstos em legislação ambiental como passíveis de recomendação pela agência reguladora, para que não ocorra sobreposição de atribuição entre agência e outra entidade. Entretanto, cabe à agência reguladora considerar esse tipo de irregularidade ambiental como não conformidade ou não. Por exemplo, a ARES-PCJ trata a ausência de outorga e o seu vencimento como não conformidade, estabelecendo o prazo de 180 dias para sua regularização.

Ressalta-se que a articulação entre agência reguladora e órgãos vinculados à saúde e ao meio ambiente, além de permitir análise integrada dos serviços públicos prestados, contribui para a eficácia da fiscalização e o reforço institucional das entidades responsáveis pelo controle de serviços públicos. Por isso, recomenda-se que a agência reguladora informe qualquer irregularidade ambiental detectada no sistema para o órgão competente.

Por fim, os itens de cunho informativo, total de 43, referem-se a elementos gerais do sistema e visam a contribuir para a composição de relatórios de fiscalização. Com exceção de sete itens, todos são abordados por, pelo menos, uma das agências consideradas neste estudo, sendo a maioria verificada pela ARES-PCJ no checklist dos relatórios analisados.

Julgou-se importante a proposição de dois documentos a serem adotados por agências reguladoras: formulário de inspeção de campo (checklist) - elencando um conjunto de perguntas sobre o sistema fiscalizado - e relação de não conformidades passíveis de serem identificadas pelo fiscal, incluindo referências legais e respectivos prazos de adequação, considerando que:

- um dos objetivos da regulação é o estabelecimento de padrões e normas para a adequada prestação dos serviços e satisfação dos usuários;

- procedimentos e documentos padrões auxiliam no desenvolvimento do trabalho dos fiscais em campo, contribuem para a elaboração de relatório de fiscalização mais fundamentado e determinação eficaz das não conformidades, e ainda permitem tratamento isonômico aos prestadores de serviços.

Ressalta-se que cada agência reguladora deve considerar sua estrutura organizacional e as peculiaridades dos sistemas regulados na definição de procedimentos e documentos.
O formulário de inspeção de campo recomendado contempla todos os 179 itens abordados neste estudo, entretanto, sugere-se que todos estejam em formato de pergunta. O documento pode ser incluído no Manual de Fiscalização da agência, que visa a abordar todo o processo de fiscalização, devendo esta se dar de forma planejada e objetiva. Como observado no manual disponibilizado pela agência do estado do Espírito Santo, podem ser estabelecidos procedimentos a serem seguidos pelos fiscais desde a preparação para a fiscalização até o acompanhamento da correção das irregularidades pelo prestador de serviços, além de documentos padrões como minutas de ofícios e modelos de relatório de fiscalização, parecer técnico e termo de notificação. $\mathrm{O}$ formato proposto para o formulário é apresentado na Figura 2 e se assemelha aos disponíveis no sítio eletrônico da ARCE e ARSI.

Sugere-se que as agências estabeleçam resolução específica que apresente todas as não conformidades às quais o SAA esteja sujeito. Adicionalmente, devem ficar claros o dispositivo normativo de referência, de forma a garantir a legalidade em caso de notificação pela agência, e a determinação do prazo para correção da não conformidade. Essa informação auxilia o ente regulador no controle das correções e na tomada de decisão no que se refere à aplicação de sanções e penalidades. Salienta-se que o registro fotográfico datado no relatório de fiscalização é instrumento fundamental na comprovação da existência de não conformidade no SAA.

A relação de não conformidades proposta contempla todos os 80 itens abordados neste estudo. O formato apresentado na Figura 3 é semelhante ao considerado na Resolução ARES-PCJ no 48/14 (ARES-PCJ, 2014c).

$\mathrm{Na}$ Figura 4, apresenta-se a distribuição das não conformidades em relação aos aspectos operacionais considerados neste estudo.

Observa-se que a estação de tratamento apresenta maior quantitativo de não conformidades, seguida do reservatório e da rede de distribuição, resultado coerente, visto que são unidades do sistema fundamentais para garantia da qualidade da água e da perenidade do abastecimento à população.

O quantitativo de itens obtidos neste estudo, com destaque àqueles passíveis de serem enquadrados como não conformidades, mostra a fragilidade à qual a ação de fiscalização de agências reguladoras está sujeita, visto a abrangência do que deve ser observado pelo fiscal

\begin{tabular}{|c|c|c|c|c|c|}
\hline \multicolumn{6}{|c|}{ Formulário de Inspeção } \\
\hline Município Fiscalizado: & \multicolumn{5}{|c|}{ Nome da Unidade: } \\
\hline Itens Fiscalizados & $\mathrm{s}$ & N & NA & Enquadramento & Observação \\
\hline \multicolumn{6}{|l|}{ I. Unidade do SAA } \\
\hline & & & & & \\
\hline
\end{tabular}

SAA: sistema de abastecimento de água; S: sim; N: não; NA: não se aplica.

Figura 2 - Proposta de formulário para inspeção de campo de sistemas de abastecimento de água (SAA). 


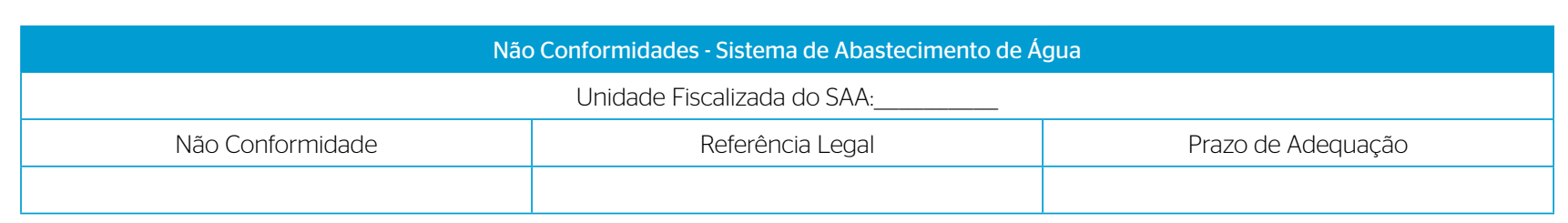

Figura 3 - Proposta de tabela para não conformidades na fiscalização de sistemas de abastecimento de água.

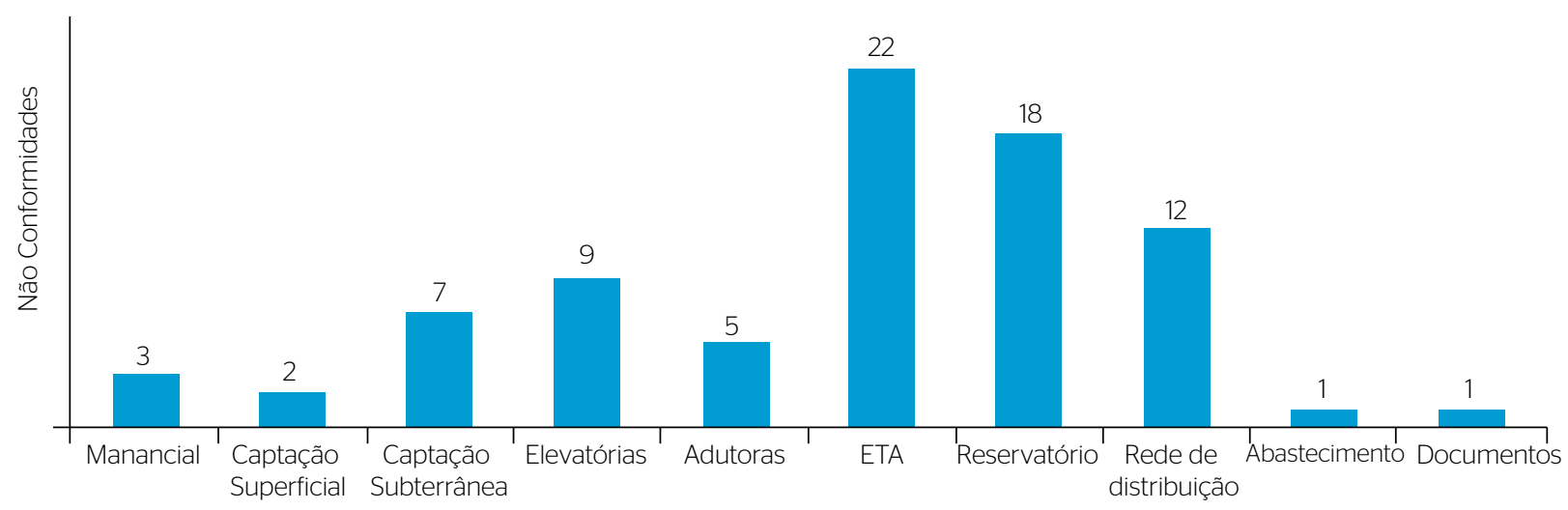

ETA: estação de tratamento de água.

Figura 4 - Distribuição das não conformidades em relação aos itens e às etapas inerentes aos sistemas de abastecimento de água.

em campo e sua responsabilidade pelo resultado final da fiscalização. Nesse sentido, todas as propostas apresentadas neste trabalho convergem para a ratificação da importância do papel da fiscalização operacional dos serviços públicos de abastecimento para averiguação de sua qualidade e continuidade.

O prestador de serviços tem papel fundamental para manutenção desses princípios, como responsável por operar o sistema, mas cabe à agência reguladora avaliar o nível de conformidade do mesmo em relação às normas legais e técnicas, de forma a garantir aos usuários e ao poder concedente a qualidade da prestação do serviço.

Adicionalmente, a padronização de itens passíveis de serem enquadrados como não conformidades facilita o benchmarking entre os diversos prestadores de serviços do Brasil, instrumento que busca incentivar a melhoria contínua dos serviços prestados. Benchmarking é uma ferramenta de comparação de ideias e práticas entre organizações e/ou entre partes da mesma organização, com o objetivo de melhorar continuamente o desempenho das mesmas" (GUIMARÃES et al., 2013, p. 35). Para isso, sugere-se que a ABAR reúna agências interessadas para discussão detalhada sobre a fiscalização dos serviços e as condições ideais de operação e manutenção de sistemas de abastecimento e esgotamento sanitário para enquadramento de não conformidades, a fim de promover o aprimoramento e a consolidação das melhores práticas de fiscalização em evidência no país.

\section{CONCLUSÕES}

Com base na revisão da literatura e nos resultados, pode-se concluir que as entidades reguladoras dos serviços públicos de saneamento têm a difícil missão de definir as condições ideais da prestação dos serviços de abastecimento de água, a fim de consolidar instrumento comum para avaliar a qualidade dos serviços.

A padronização e a otimização de procedimentos e documentos pelas agências reguladoras destacam-se sob o ponto de vista do aprimoramento da atividade regulatória, especialmente no que se refere à ação de fiscalização, que busca verificar o cumprimento dos dispositivos normativos considerados pelo ente regulador. Além disso, o estabelecimento de padrão quanto aos itens passíveis de serem enquadrados como não conformidades facilita a avaliação comparativa da qualidade da prestação dos serviços entre as diversas entidades do setor, visando a incentivar a busca pela melhoria contínua dos serviços prestados e consequente satisfação dos usuários.

Sob essa perspectiva, este trabalho propôs uma relação de 179 itens para verificação em fiscalização direta de sistemas de abastecimento de água, sendo determinados, nesse conjunto, 80 não conformidades. Neste cenário, maior destaque coube à estação de tratamento, unidade com maior quantitativo de não conformidades (22). Um grupo de 56 itens foi tratado como sujeito à recomendação da agência e os 43 restantes, como itens de caráter informativo. 


\section{REFERÊNCIAS}

AGÊNCIA REGULADORA DE SANEAMENTO BÁSICO E INFRAESTRUTURA VIÁRIA DO ESPÍRITO SANTO. (2011) Checklist. Vitória: Agência Reguladora de Saneamento Básico e Infraestrutura Viária do Espírito Santo. Disponível em: <https://arsp.es.gov.br/ Media/arsi/Saneamento/Fiscaliza\%C3\%A7\%C3\%A3o/Manual\%2O e\%2OChecklist/CHECK\%2OLIST\%2O_\%2OVERSAO\%2O11.pdf>. Acesso em: 22 abr. 2016.

(2018) Manual de Fiscalização. Vitória: Agência Reguladora de Saneamento Básico e Infraestrutura Viária do Espírito Santo. Disponível em: <https://arsp.es.gov.br/Media/arsi/Saneamento/ Fiscaliza\%C3\%A7\%C3\%A30/Manual\%20e\%20Checklist/ Manual\%2Ode\%2OFiscaliza\%C3\%A7\%C3\%A3o.pdf>. Acesso em: 22 abr. 2016.

(2010) Resolução ARSI no 008/10. Vitória: Agência Reguladora de Saneamento Básico e Infraestrutura Viária do Espírito Santo. Disponível em: <https://arsp.es.gov.br/Media/ arsi/Legisla\%C3\%A7\%C3\%A3o/Resolu\%C3\%A7\%C3\%B5es\%20 Saneamento\%2OB\%C3\%A1sico/ARSI/ResolucaoSaneaO08_2010. pdf>. Acesso em: 22 abr. 2016.

AGÊNCIA REGULADORA DE SERVIÇOS PÚBLICOS DELEGADOS DO ESTADO DO CEARÁ. (2010a) Resolução ARCE no 130/10. Fortaleza, 2016. Disponível em: <https:// www.arce.ce.gov.br/download/resolucoes-arce/>. Acesso em: 22 abr. 2016.

(2010b) Resolução ARCE no 147/10. Fortaleza. Disponível em: <https://www.arce.ce.gov.br/download/resolucoes-arce/>. Acesso em: 22 abr. 2016.

AGÊNCIA REGULADORA DOS SERVIÇOS DE SANEAMENTO DAS BACIAS DOS RIOS PIRACICABA, CAPIVARI E JUNDIAI (ARES-PCJ). (2014a) Relatório de Fiscalização Técnica dos Sistemas de Água e Esgoto do Município de Araraquara. Americana: ARES-PCJ. Disponível em: <http://www.arespcj. com.br/arquivos/67786_R1_Araraquara_internet.pdf>. Acesso em: 22 abr. 2016.

(2014b) Relatório de Fiscalização Técnica dos Sistemas de Água e Esgoto do Município de Cerquilho. Americana: ARESPCJ. Disponível em: <http://www.arespcj.com.br/arquivos/16031_ RELATORIO_DE_FISCALIZA\%C3\%87\%C3\%830_-_Cerquilho_ internet.pdf>. Acesso em: 22 abr. 2016.

(2014c) Resolução ARES-PCJ no 48/14. Americana: ARES-PCJ. Disponível em: <http://www.arespcj.com. br/arquivos/82274_Resolu\%C3\% A7\% C3\% A3o_n\%C2\% BA_48_2014_-_N\%C3\%A3o_Conformidades_-_Editada.pdf $>$. Acesso em: 22 abr. 2016.

(2014d) Resolução ARES-PCJ no 50/14. Americana: ARES-PCJ. Disponível em: <http://www.arespcj.com. br/arquivos/12629_Resolu\%C3\% A7\% C3\% A30_n\%C2\% BA_50_2014_-_Condi\%C3\%A7\%C3\%B5es_Gerais_-_2.pdf $>$. Acesso em: 22 abr. 2016.
ARAÚJO, A.P.M.; TAVARES, R.G.; BARBOSA, P.R.P.; SOUZA, S.M.Q. (2009) Fiscalização da Prestação dos Serviços de Abastecimento de Água e de Esgotamento Sanitário. In: GALVÃO JUNIOR, A.C.; XIMENES, M.M.A.F. (orgs.). Regulação: Normatização da Prestação de Serviços de Água e Esgoto. Fortaleza: Expressão, 2009. v. 2. p. 271-284.

ASSOCIAÇÃO BRASILEIRA DE AGÊNCIAS DE REGULAÇÃO (ABAR). (2015) Agências Associadas. Brasília: ABAR. Disponível em: <http:// www.abar.org.br/>. Acesso em: 27 ago. 2016.

ASSOCIAÇÃO BRASILEIRA DE NORMAS TÉCNICAS (ABNT). (1991) NBR 12215: Projeto da adutora para abastecimento público (NB 591). Rio de Janeiro: ABNT.

(1992a) NBR 12214: Projeto de sistema de bombeamento de água para abastecimento público. Rio de Janeiro: ABNT.

(1992b) NBR 12216: Projeto de estação e tratamento de água para abastecimento público. Rio de Janeiro: ABNT.

(1992c) NBR 12244: Construção de poço para captação subterrânea. Rio de Janeiro: ABNT.

(1994a) NBR 12217: Projeto de reservatório de distribuição de água para abastecimento público. Rio de Janeiro: ABNT.

(1994b) NBR 12218: Projeto de rede de distribuição de água para abastecimento público. Rio de Janeiro: ABNT.

BRASIL. (1976) Ministério da Saúde. Portaria no 635/GM/MS, de 30 de janeiro de 1976. Aprova normas e padrões sobre a fluoretação da água, tendo em vista a Lei no 6.050/74. Disponível em: <http:// www.rio.rj.gov.br/dlstatic/10112/5125585/4137805/portaria635.pdf>. Acesso em: 22 abr. 2016.

(1981) Lei no 6.938, de 31 de agosto de 1981. Dispõe sobre a Política Nacional do Meio Ambiente, seus fins e mecanismos de formulação e aplicação, e dá outras providências. Disponível em: <http://www.planalto.gov.br/ccivil_O3/leis/L6938.htm>. Acesso em: 22 abr. 2016.

(1997) Lei no 9.433, de 8 de janeiro de 1997. Institui a Política Nacional de Recursos Hídricos, cria o Sistema Nacional de Gerenciamento de Recursos Hídricos, regulamenta o inciso XIX do art. 21 da Constituição Federal, e altera o art. 10 da Lei no 8.001, de 13 de março de 1990, que modificou a Lei no 7.990, de 28 de dezembro de 1989. Disponível em: <http://www.planalto.gov.br/ ccivil_03/leis/L9433.htm>. Acesso em: 22 abr. 2016.

(2005) Decreto no 5.440, de 4 de maio de 2005. Estabelece definições e procedimentos sobre o controle de qualidade da água de sistemas de abastecimento e institui mecanismos e instrumentos para divulgação de informação ao consumidor sobre a qualidade da água para consumo humano. Disponível em: <http://www.planalto.gov.br/ccivil_03/_Ato2004-2006/2005/ Decreto/D5440.htm>. Acesso em: 22 abr. 2016 
(2007) Lei no 11.445, de 5 de janeiro de 2007. Estabelece diretrizes nacionais para o saneamento básico. Disponível em: <http://www.planalto.gov.br/ccivil_03/_ato2007-2010/2007/lei/ 111445.htm>. Acesso em: 22 abr. 2016.

(2010) Decreto no 7.217, de 21 de junho de 2010. Regulamenta a Lei no 11.445, de 5 de janeiro de 2007, que estabelece diretrizes nacionais para o saneamento básico, e dá outras providências. Disponível em: <http://www.planalto.gov.br/ccivil_03/_ato20072010/2010/decreto/D7217.htm>. Acesso em: 22 abr. 2016.

(2011) Ministério da Saúde. Portaria no 2.914, de 12 de dezembro de 2011. Dispõe sobre os procedimentos de controle e de vigilância da qualidade da água para consumo humano e seu padrão de potabilidade. Disponível em: <http://bvsms.saude. gov.br/bvs/saudelegis/gm/2011/prt2914_12_12_2011.html>. Acesso em: 22 abr. 2016.

(2016) Ministério das Cidades. Secretaria Nacional de Saneamento Ambiental (SNSA). Sistema Nacional de Informações sobre Saneamento: diagnóstico dos serviços de água e esgotos 2014. Brasília: SNSA/MCIDADES. 212 p.
ESPÍRITO SANTO. (2016) Lei Complementar no 827 de 010 de julho de 2016. Cria a Agência de Regulação de Serviços Públicos - ARSP, em decorrência da fusão da Agência Reguladora de Saneamento Básico e Infraestrutura Viária do Espírito Santo - ARSI e da Agência de Serviços Públicos de Energia do Estado do Espírito Santo ASPE e dá outras providências.

INSTITUTO BRASILEIRO DE GEOGRAFIA E ESTATÍSTICA (IBGE) Ceará. Panorama. Disponível em: <https://cidades.ibge.gov.br/ brasil/ce/panorama>. Acesso em: 2 out. 2017.

Espírito Santo. Panorama. Disponível em: <https://cidades. ibge.gov.br/brasil/es/panorama>. Acesso em: 2 out. 2017.

GALVÃO JUNIOR, A. de C. (org.). (2006) Regulação: procedimentos de fiscalização em sistema de abastecimento de água. Fortaleza: Expressão. 160 p.

GUIMARÃES, E.F.; TEMÓTEO, T.G.; MALHEIROS, T.F. (2013) Benchmarking aplicado às revisões tarifárias do saneamento. Revista DAE, n. 192, p. 34-47. http://dx.doi.org/10.4322/ dae.2014.104 
Apêndice 1 - Itens para fiscalização direta de sistema de abastecimento de água (SAA).

\begin{tabular}{|c|c|c|c|c|c|}
\hline \multirow{2}{*}{\multicolumn{2}{|c|}{ Item Fiscalizado }} & \multicolumn{3}{|c|}{ Agência Reguladora } & \multirow{2}{*}{ Enquadramento } \\
\hline & & ARES-PCJ & ARIS & ARCE & \\
\hline \multirow{5}{*}{ Manancial } & $\begin{array}{l}\text { Ausência de placa de identificação da área do } \\
\text { manancial de captação. }\end{array}$ & $x$ & $x$ & $x$ & Lei Federal no 11.445/07 - Inciso XI do Art. 20 \\
\hline & $\begin{array}{l}\text { Não é realizado monitoramento de cianobactérias } \\
\text { de acordo com o preconizado pela Portaria do } \\
\text { Ministério da Saúde vigente. }\end{array}$ & $x$ & $x$ & $x$ & Portaria do MS n².914/11 - Anexo XI \\
\hline & $\begin{array}{l}\text { Ausência de plano/registros de inspeções } \\
\text { sanitárias na área de entorno do manancial para } \\
\text { averiguar potenciais fontes poluidoras. }\end{array}$ & $x$ & - & $x$ & Portaria do MS n 2.914/11 - Inciso IV do Art. 130 \\
\hline & $\begin{array}{l}\text { Existem fontes poluidoras (pontuais ou difusas) } \\
\text { próximo à área de captação da manancial? }\end{array}$ & $x$ & $x$ & $x$ & Item sujeito à recomendação da Agência \\
\hline & Há indícios de eutrofização no manancial? & $x$ & - & $x$ & Item sujeito à recomendação da Agência \\
\hline \multirow{8}{*}{$\begin{array}{l}\text { Captação } \\
\text { Superficial }\end{array}$} & Qual o tipo de captação? (flutuante, tomada dágua, etc) & $x$ & - & - & Item Informativo \\
\hline & Qual é a vazão captada média (I/S)? & $x$ & - & $x$ & Item Informativo \\
\hline & Qual é a vazão outorgada (I/S)? & $x$ & - & - & Item Informativo \\
\hline & $\begin{array}{l}\text { A vazão média captada não atende à demanda } \\
\text { da população. }\end{array}$ & - & $x$ & $x$ & Decreto Federal 7.217/10 - Art. 170 \\
\hline & Ausência de outorga de captação ou outorga vencida. & $x$ & $x$ & $x$ & $\begin{array}{l}\text { Lei Federal no 9.433/97 - Art. } 120 \text { - Item } \\
\text { sujeito à recomendação da Agência }\end{array}$ \\
\hline & $\begin{array}{l}\text { A área de captação não está cercada ou murada, } \\
\text { condição que pode facilitar o acesso de estranhos. }\end{array}$ & $x$ & $x$ & $x$ & Lei Federal no 11.445/07 - Inciso XI do Art. $2^{\circ}$ \\
\hline & $\begin{array}{l}\text { Quais os dispositivos existentes? (barragem de nível, } \\
\text { tomada dágua, flutuador, crivo, grade, caixa de areia, etc) }\end{array}$ & $x$ & - & $x$ & Item Informativo \\
\hline & $\begin{array}{l}\text { Os dispositivos existentes apresentam bom } \\
\text { estado de limpeza, conservação e manutenção? }\end{array}$ & - & - & $x$ & Item sujeito à recomendação da Agência \\
\hline \multirow{17}{*}{$\begin{array}{l}\text { Captação } \\
\text { Subterrânea }\end{array}$} & Qual é a vazão captada média (I/s)? & $x$ & - & - & Item Informativo \\
\hline & Qual é a vazão outorgada (I/S)? & - & - & - & Item Informativo \\
\hline & $\begin{array}{l}\text { A vazão média captada não atende à demanda } \\
\text { da população. }\end{array}$ & - & $x$ & $x$ & Decreto Federal 7.217/10 - Art. 170 \\
\hline & Ausência de outorga de captação ou outorga vencida. & $x$ & - & - & $\begin{array}{l}\text { Lei Federal no 9.433/97 - Art. } 120 \text { - Item } \\
\text { sujeito à recomendação da Agência }\end{array}$ \\
\hline & Ausência de placa de identificação da área do poço. & $x$ & $x$ & $x$ & Lei Federal no 11.445/07 - Inciso XI do Art. 20 \\
\hline & $\begin{array}{l}\text { A área do poço não está cercada ou murada, } \\
\text { condição que pode facilitar o acesso de estranhos. }\end{array}$ & $x$ & - & - & Lei Federal no 11.445/O7 - Inciso XI do Art. $2^{\circ}$ \\
\hline & $\begin{array}{l}\text { Ausência bomba reserva em estoque, a ser } \\
\text { instalada para acionamento imediato, quando } \\
\text { houver pane no principal. }\end{array}$ & $x$ & - & $x$ & NBR 12214/92 - item 5.3 .2 \\
\hline & $\begin{array}{l}\text { Há proximidade do poço com fonte poluidora? - } \\
\text { fossa séptica, por exemplo. }\end{array}$ & - & - & $x$ & Item sujeito à recomendação da Agência \\
\hline & Ausência de laje de proteção do poço. & $x$ & $x$ & $x$ & NBR 12244/92 - item 6.2.4.1 \\
\hline & $\begin{array}{l}\text { Ausência de declividade do centro para a borda } \\
\text { da laje de proteção. }\end{array}$ & - & - & $x$ & NBR 12244/92 - item 6.2.4.2 \\
\hline & Presença de vazamento(s) aparente(s). & $x$ & - & - & Lei Federal no 11.445/07 - Inciso XI do Art. 20 \\
\hline & $\begin{array}{l}\text { As instalações elétricas do poço estão adequadas? } \\
\text { - fiação elétrica não aparente e protegida. }\end{array}$ & $x$ & $x$ & $x$ & Item sujeito à recomendação da Agência \\
\hline & O quadro de força está funcionando normalmente? & $x$ & $x$ & $x$ & Item sujeito à recomendação da Agência \\
\hline & Existe horímetro em funcionamento? & $x$ & $x$ & $x$ & Item Informativo \\
\hline & Existe dispositivo de proteção antigolpe? & $x$ & - & - & Item Informativo \\
\hline & Existe iluminação para trabalhos noturnos na área do poço? & $x$ & $x$ & $x$ & Item sujeito à recomendação da Agência \\
\hline & $\begin{array}{l}\text { A área do poço apresenta bom estado de limpeza, } \\
\text { conservação, manutenção e organização? }\end{array}$ & - & - & $x$ & Item sujeito à recomendação da Agência \\
\hline
\end{tabular}


Apêndice 1 - Continuação.

\begin{tabular}{|c|c|c|c|c|c|}
\hline \multirow{2}{*}{\multicolumn{2}{|c|}{ Item Fiscalizado }} & \multicolumn{3}{|c|}{ Agência Reguladora } & \multirow{2}{*}{ Enquadramento } \\
\hline & & ARES-PC J & ARIS & ARCE & \\
\hline \multirow{15}{*}{ Elevatórias* } & Qual o tipo de elevatória (água bruta ou água tratada)? & - & - & - & Item Informativo \\
\hline & $\begin{array}{l}\text { Ausência de placa de identificação da área da } \\
\text { estação elevatória. }\end{array}$ & $x$ & $x$ & $x$ & Lei Federal no 11.445/07 - Inciso XI do Art. 20 \\
\hline & $\begin{array}{l}\text { A área da elevatória não está cercada ou } \\
\text { murada, condição que pode facilitar o acesso } \\
\text { de estranhos. }\end{array}$ & $x$ & $x$ & $x$ & Lei Federal no 11.445/O7 - Inciso XI do Art. 20 \\
\hline & A estação elevatória está sujeita a enchentes. & - & - & - & NBR 12214/92 - item 5.10.1.2 \\
\hline & $\begin{array}{l}\text { Ausência bomba reserva devidamente instalada } \\
\text { para acionamento imediato, quando houver pane } \\
\text { na principal. }\end{array}$ & $x$ & $x$ & $x$ & NBR 12214/92 - item 5.3 .2 \\
\hline & $\begin{array}{l}\text { A área da elevatória apresenta } \\
\text { bom estado de limpeza, conservação, } \\
\text { manutenção e organização? }\end{array}$ & $x$ & $x$ & $x$ & Item sujeito à recomendação da Agência \\
\hline & Presença de vazamento(s) aparente(s). & $x$ & - & - & Lei Federal n 11.445/07 - Inciso XI do Art. 20 \\
\hline & $\begin{array}{l}\text { Ausência ou não funcionamento de manômetro } \\
\text { individual nos conjuntos de recalque. }\end{array}$ & $x$ & - & - & NBR 12214/92 - item 5.8 .4 \\
\hline & $\begin{array}{l}\text { A sala de bombas não permite livre circulação } \\
\text { de pessoas ou de equipamento, visando a } \\
\text { manutenção, montagem, desmontagem, entrada } \\
\text { e saída de equipamentos. }\end{array}$ & $x$ & $x$ & $x$ & NBR 12214/92 - item 5.10 .1 \\
\hline & $\begin{array}{l}\text { Ausência de iluminação natural ou artificial na } \\
\text { estação elevatória. }\end{array}$ & $x$ & - & X & NBR 12214/92 - item 5.11 .1 \\
\hline & $\begin{array}{l}\text { Ausência de ventilação natural ou forçada, } \\
\text { prejudicando a livre circulação do ar. }\end{array}$ & $x$ & - & $x$ & NBR 12214/92 - item 5.11 .2 \\
\hline & $\begin{array}{l}\text { Os quadros de comando e de força estão } \\
\text { funcionando normalmente? }\end{array}$ & $x$ & $x$ & $x$ & Item sujeito à recomendação da Agência \\
\hline & Existem dispositivos de proteção antigolpe? & $x$ & $x$ & $x$ & Item Informativo \\
\hline & $\begin{array}{l}\text { As bombas possuem horímetro (ou equivalente) } \\
\text { individual funcionando normalmente? }\end{array}$ & $x$ & $x$ & $x$ & Item Informativo \\
\hline & $\begin{array}{l}\text { É realizada a comunicação com a ETA? Quais os } \\
\text { meios de comunicação? }\end{array}$ & $x$ & - & - & Item Informativo \\
\hline \multirow{11}{*}{ Adutoras* } & Qual o tipo de adutora (água bruta ou água tratada)? & - & - & - & Item Informativo \\
\hline & $\begin{array}{l}\text { Ausência de ventosa, imediatamente antes e logo } \\
\text { após as descargas de água. }\end{array}$ & $x$ & $x$ & $x$ & NBR 12215/91 - item 5.6 .1 \\
\hline & $\begin{array}{l}\text { Ausência de dispositivos de descarga de água } \\
\text { nos pontos baixos da adutora. }\end{array}$ & $x$ & $x$ & $x$ & NBR 12215/91 - item 5.6 .2 \\
\hline & $\begin{array}{l}\text { É realizada manutenção preventiva nas adutoras } \\
\text { (dispositivos de descarga,ventosas, limpeza)? Qual } \\
\text { a frequência? }\end{array}$ & - & - & $x$ & Item sujeito à recomendação da Agência \\
\hline & $\begin{array}{l}\text { As caixas de proteção dos componentes estão } \\
\text { em boas condições? }\end{array}$ & - & $x$ & $x$ & Item sujeito à recomendação da Agência \\
\hline & $\begin{array}{l}\text { Dificuldade de acesso para trabalhos de instalação } \\
\text { ou manutenção ao longo da linha de adução. }\end{array}$ & - & $x$ & $x$ & NBR 12215/91 - item 5.1.5.1 \\
\hline & $\begin{array}{l}\text { Existem problemas recorrentes de vazameto? } \\
\text { Verificar ocorrências operacionais. }\end{array}$ & - & $x$ & $x$ & Item sujeito à recomendação da Agência \\
\hline & $\begin{array}{l}\text { Ausência de medidor de vazão, com indicação } \\
\text { local ou com equipamento de telemetria. }\end{array}$ & - & $x$ & $x$ & NBR 12215/91 - item 5.6 .6 \\
\hline & $\begin{array}{l}\text { Ausência de dispositivo para aferição periódica } \\
\text { do medidor de vazão. }\end{array}$ & - & - & - & NBR 12215/91 - item 5.6 .7 \\
\hline & Existem dispositivos de proteção antigolpe? & - & $x$ & - & Item sujeito à recomendação da Agência \\
\hline & Existem estações pitométricas? & - & - & $x$ & Item sujeito à recomendação da Agência \\
\hline
\end{tabular}


Apêndice 1 - Continuação.

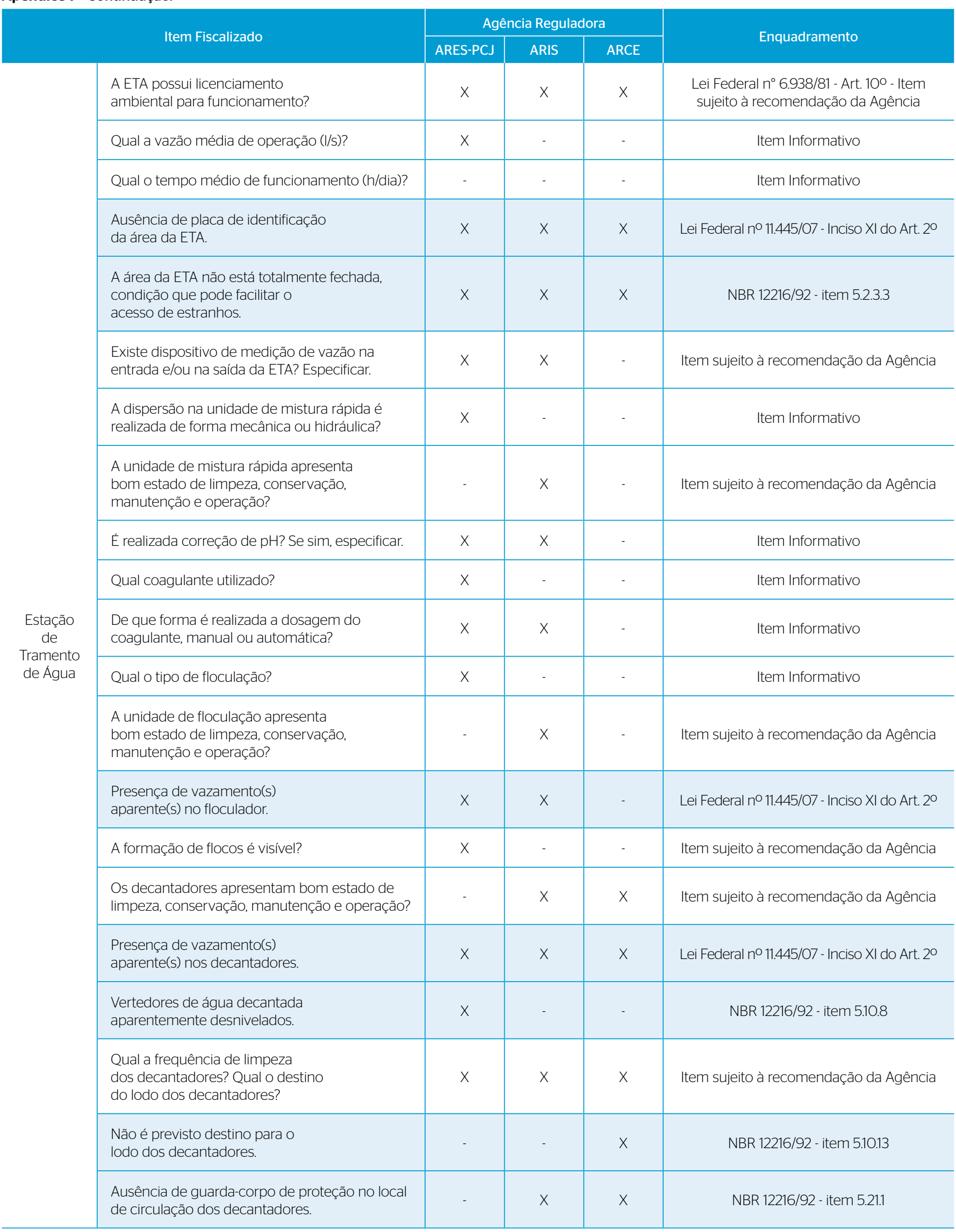


Apêndice 1 - Continuação.

\begin{tabular}{|c|c|c|c|c|c|}
\hline \multirow{2}{*}{\multicolumn{2}{|c|}{ Item Fiscalizado }} & \multicolumn{3}{|c|}{ Agência Reguladora } & \multirow{2}{*}{ Enquadramento } \\
\hline & & ARES-PCJ & ARIS & ARCE & \\
\hline \multirow{24}{*}{$\begin{array}{l}\text { Estação de } \\
\text { Tramento } \\
\text { de Água }\end{array}$} & Há passagem de flocos para os filtros? & $x$ & - & - & Item sujeito à recomendação da Agência \\
\hline & $\begin{array}{l}\text { A unidade de filtração apresenta bom estado de } \\
\text { limpeza, conservação, manutenção e operação? }\end{array}$ & - & $x$ & $x$ & Item sujeito à recomendação da Agência \\
\hline & $\begin{array}{l}\text { Presença de vazamentos aparentes nas } \\
\text { tubulações e registros dos filtros. }\end{array}$ & $x$ & $x$ & $x$ & Lei Federal no 11.445/O7 - Inciso XI do Art. 20 \\
\hline & $\begin{array}{l}\text { Ausência de guarda-corpo de proteção nas } \\
\text { instalações da filtração. }\end{array}$ & - & $x$ & $x$ & NBR 12216/92 - item 5.21 .1 \\
\hline & $\begin{array}{l}\text { Em caso de filtração rápida, ausência de } \\
\text { tomada de água na saída de cada filtro para } \\
\text { determinação de turbidez. }\end{array}$ & - & - & - & NBR 12216/92 - item 5.21 .22 \\
\hline & Qual a frequência de limpeza dos filtros (horas)? & $x$ & $x$ & - & Item sujeito à recomendação da Agência \\
\hline & $\begin{array}{l}\text { Qual o volume de lavagem dos filtros? É menor } \\
\text { ou igual a } 5 \% \text { do total produzido na ETA? }\end{array}$ & - & $x$ & $x$ & Item sujeito à recomendação da Agência \\
\hline & Qual o destino da água de lavagem dos filtros? & $x$ & $x$ & $x$ & Item Informativo \\
\hline & $\begin{array}{l}\text { Há carreamento do leito filtrante? (observar na } \\
\text { caixa de descarga de lavagem) }\end{array}$ & - & $x$ & $x$ & Item sujeito à recomendação da Agência \\
\hline & $\begin{array}{l}\text { Em caso de filtração ascendente, os filtros possuem } \\
\text { tampas de proteção interiças e em boas condições? }\end{array}$ & - & - & $x$ & Item sujeito à recomendação da Agência \\
\hline & $\begin{array}{l}\text { Em caso de filtração ascendente, há presença de } \\
\text { bolhas na filtração? }\end{array}$ & - & $x$ & $x$ & Item sujeito à recomendação da Agência \\
\hline & Qual o tipo de desinfecção utilizada? & $x$ & - & - & Item Informativo \\
\hline & $\begin{array}{l}\text { Como é realizada a adição de flúor, } \\
\text { manual ou automatizada? }\end{array}$ & $x$ & - & - & Item Informativo \\
\hline & $\begin{array}{l}\text { O funcionamento da flouretação } \\
\text { ocorre normalmente, sem apresentar } \\
\text { problemas operacionais? }\end{array}$ & - & $x$ & - & Item sujeito à recomendação da Agência \\
\hline & $\begin{array}{l}\text { A casa de química apresenta } \\
\text { bom estado de limpeza, conservação, } \\
\text { manutenção e organização? }\end{array}$ & $x$ & $x$ & $x$ & Item sujeito à recomendação da Agência \\
\hline & $\begin{array}{l}\text { A área de depósito de produtos químicos não } \\
\text { permite livre acesso entre as pilhas de sacarias, } \\
\text { com ventilação conveniente, de forma a evitar } \\
\text { excesso de umidade. }\end{array}$ & $x$ & $x$ & $x$ & NBR 12216/92 - item 5.15.4.2 \\
\hline & $\begin{array}{l}\text { Os produtos químicos ensacados de sulfato de } \\
\text { alumínio não estão empilhados em local coberto, } \\
\text { seco e isolados das paredes e do piso. }\end{array}$ & - & - & $x$ & NBR 12216/92 - item 5.17.2.3 \\
\hline & $\begin{array}{l}\text { Os produtos químicos ensacados de cal hidratada } \\
\text { não estão empilhados em local coberto, seco e } \\
\text { isolados das paredes e do piso. }\end{array}$ & - & - & $x$ & NBR 12216/92 - item 5.18 .3 \\
\hline & $\begin{array}{l}\text { É realizado controle de qualidade dos produtos } \\
\text { químicos (validade e identificação)? }\end{array}$ & $x$ & $x$ & $x$ & Item sujeito à recomendação da Agência \\
\hline & $\begin{array}{l}\text { Os tanques de dosagem de produtos químicos } \\
\text { e bomba dosadora estão em boas condições } \\
\text { de manutenção? }\end{array}$ & - & $x$ & $x$ & Item sujeito à recomendação da Agência \\
\hline & $\begin{array}{l}\text { Ausência de condições de segurança no depósito } \\
\text { para armazenamento ou dosagem de cloro gás } \\
\text { (ventilação natural e forçada; interruptores dos } \\
\text { aparelhos do lado de fora do recinto; cilindros } \\
\text { protegidos da incidência direta da luz solar). }\end{array}$ & $x$ & $x$ & $x$ & NBR 12216/92 - item 5.19 .6 \\
\hline & $\begin{array}{l}\text { Os operadores utilizam equipamento de proteção } \\
\text { individual (luvas, óculos de proteção)? }\end{array}$ & $x$ & $x$ & - & Item sujeito à recomendação da Agência \\
\hline & Existe kit de emergência disponível no local? & $x$ & $x$ & $x$ & Item sujeito à recomendação da Agência \\
\hline & Ausência de chuveiro de emergência. & $x$ & - & - & NBR 12216/92 - item 5.21 .4 \\
\hline
\end{tabular}


Apêndice 1 - Continuação.

\begin{tabular}{|c|c|c|c|c|c|}
\hline \multirow{2}{*}{\multicolumn{2}{|c|}{ Item Fiscalizado }} & \multicolumn{3}{|c|}{ Agência Reguladora } & \multirow{2}{*}{ Enquadramento } \\
\hline & & ARES-PC J & ARIS & ARCE & \\
\hline \multirow{18}{*}{$\begin{array}{l}\text { Estação de } \\
\text { Tramento } \\
\text { de Água }\end{array}$} & $\begin{array}{l}\text { Os operadores recebem treinamento para } \\
\text { manipulação dos produtos químicos? }\end{array}$ & - & $x$ & $x$ & Item sujeito à recomendação da Agência \\
\hline & $\begin{array}{l}\text { O laboratório apresenta bom estado de limpeza, } \\
\text { conservação, manutenção e organização? }\end{array}$ & $x$ & $x$ & $x$ & Item sujeito à recomendação da Agência \\
\hline & $\begin{array}{l}\text { O laboratório não é iluminado e/ou ventilado } \\
\text { natural ou artificialmente. }\end{array}$ & - & - & - & NBR 12216/92 - item 5.20 .4 \\
\hline & $\begin{array}{l}\text { Os equipamentos de análises estão em bom } \\
\text { estado de conservação? }\end{array}$ & - & $x$ & $x$ & Item sujeito à recomendação da Agência \\
\hline & Os equipamentos de análises estão calibrados? & - & $x$ & $x$ & Item sujeito à recomendação da Agência \\
\hline & $\begin{array}{l}\text { Existem armários para guardar } \\
\text { reagentes e vidrarias? }\end{array}$ & - & $x$ & $x$ & Item sujeito à recomendação da Agência \\
\hline & $\begin{array}{l}\text { Os reagentes estão dentro do } \\
\text { prazo de validade? }\end{array}$ & - & $x$ & $x$ & Item sujeito à recomendação da Agência \\
\hline & $\begin{array}{l}\text { O operador está apto para operar os aparelhos } \\
\text { do laboratório da ETA, inclusive calibrá-los } \\
\text { quando necessário? }\end{array}$ & - & $x$ & $x$ & Item sujeito à recomendação da Agência \\
\hline & $\begin{array}{l}\text { É realizada comunicação do } \\
\text { operador com outras unidades? } \\
\text { Quais os meios de comunicação? }\end{array}$ & $x$ & - & $x$ & Item Informativo \\
\hline & $\begin{array}{l}\text { Quais os parâmetros de } \\
\text { qualidade são controlados? }\end{array}$ & $x$ & $x$ & $x$ & Item Informativo \\
\hline & $\begin{array}{l}\text { Existem registros sobre a qualidade da água } \\
\text { bruta e tratada? }\end{array}$ & - & $x$ & $x$ & Item sujeito à recomendação da Agência \\
\hline & $\begin{array}{l}\text { Não realização de controle de parâmetros } \\
\text { mínimos do processo no laboratório (pH; } \\
\text { alcalinidade; turbidez; cor; cloro; flúor; alumínio } \\
\text { residual e coagulação). }\end{array}$ & $x$ & - & - & NBR 12216/92 - item 5.20.1.3 \\
\hline & $\begin{array}{l}\text { Existe equipamento para realização de teste de } \\
\text { jarros ou similar? O equipamento está em bom } \\
\text { estado de conservação? }\end{array}$ & $x$ & $x$ & - & Item sujeito à recomendação da Agência \\
\hline & $\begin{array}{l}\text { Não realização de teste de } \\
\text { jarros ou metodologia similar para } \\
\text { adequação da coagulação. }\end{array}$ & $x$ & $x$ & - & NBR 12216/92 - item 5.20.1.3 \\
\hline & $\begin{array}{l}\text { Descumprir ou não monitorar os padrões } \\
\text { de potabilidade da água na saída da ETA } \\
\text { estabelecidos na Portaria do Ministério da } \\
\text { Saúde vigente. }\end{array}$ & $x$ & $x$ & $x$ & Portaria do MS n².914/11 - Anexos I e XII \\
\hline & $\begin{array}{l}\text { Descumprimento do número mínimo de } \\
\text { amostras para controle da qualidade da água na } \\
\text { saída da ETA. }\end{array}$ & - & $x$ & $x$ & Portaria do MS n².914/11 - Anexos XII e XIII \\
\hline & $\begin{array}{l}\text { Descumprimento da frequência mínima de } \\
\text { coleta para análise da qualidade da água na } \\
\text { saída da ETA. }\end{array}$ & - & $x$ & $x$ & Portaria do MS n².914/11 - Anexos XII e XIII \\
\hline & $\begin{array}{l}\text { Descumprir ou não monitorar o parâmetro } \\
\text { turbidez na saída do filtro, antes da adição de } \\
\text { produtos químicos. }\end{array}$ & - & $x$ & - & Portaria do MS n 2.914/11 - Anexo II \\
\hline
\end{tabular}


Apêndice 1 - Continuação.

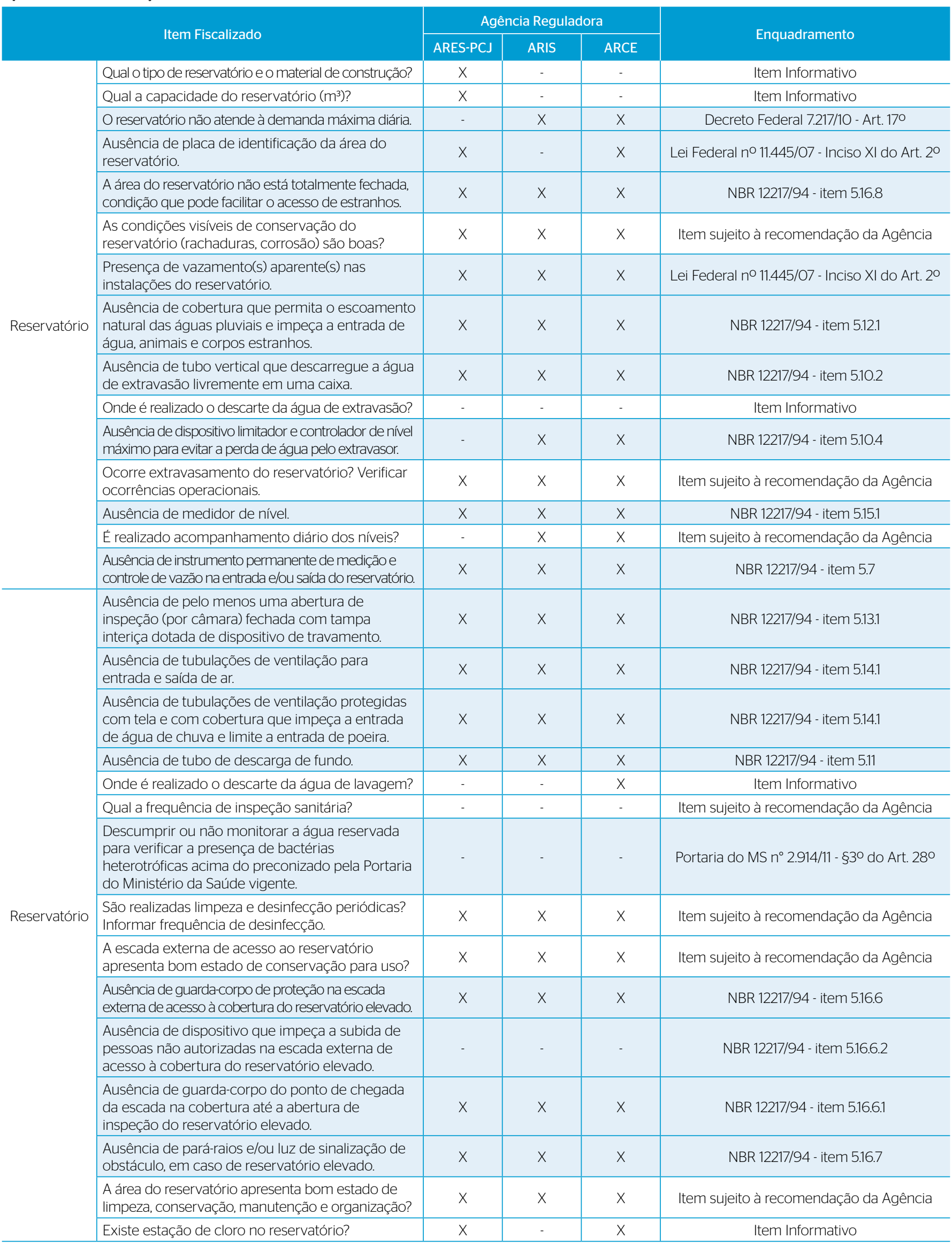


Apêndice 1 - Continuação.

\begin{tabular}{|c|c|c|c|c|c|}
\hline \multirow{2}{*}{\multicolumn{2}{|c|}{ Item Fiscalizado }} & \multicolumn{3}{|c|}{ Agência Reguladora } & \multirow{2}{*}{ Enquadramento } \\
\hline & & ARES-PCJ & ARIS & ARCE & \\
\hline \multirow{16}{*}{$\begin{array}{l}\text { Rede de } \\
\text { Distribuição }\end{array}$} & $\begin{array}{l}\text { A pressão estática máxima em determinada } \\
\text { região está acima de } 50 \text { mca. }\end{array}$ & - & $x$ & $x$ & NBR 12218/94 - item 5.4 .1 \\
\hline & $\begin{array}{l}\text { A pressão dinâmica mínima em determinada } \\
\text { reqião está abaixo de } 10 \text { mca. }\end{array}$ & - & $x$ & $x$ & NBR 12218/94 - item 5.4.1 \\
\hline & $\begin{array}{l}\text { Ausência de setorização da rede de distribuição } \\
\text { em zonas de pressão. }\end{array}$ & $x$ & $x$ & - & NBR 12218/94 - item 5.4.1.1 \\
\hline & Existe programa de redução de pressão? & $x$ & - & - & Item sujeito à recomendação da Agência \\
\hline & $\begin{array}{l}\text { O abastecimento não é contínuo - determinada } \\
\text { região está sujeita a intermitência. }\end{array}$ & $x$ & $x$ & $x$ & Decreto Federal 7.217/10 - Art. 170 \\
\hline & $\begin{array}{l}\text { Os usuários e/ou ente regulador não são previamente } \\
\text { informados em caso de paralisação programada. }\end{array}$ & $x$ & $x$ & $x$ & Lei Federal n 11.445/07 - $\S 1^{\circ}$ do Art. $40^{\circ}$ \\
\hline & $\begin{array}{l}\text { Ausência de válvulas de descarga em pontos } \\
\text { baixos da rede de determinada região. }\end{array}$ & - & $x$ & $x$ & NBR 12218/94 - item 5.10 .2 \\
\hline & $\begin{array}{l}\text { A(s) válvula(s) de descarga não estão } \\
\text { funcionando corretamente em determinada } \\
\text { região - esvaziamento total da tubulação de forma } \\
\text { a impedir entrada de água. }\end{array}$ & - & $x$ & $x$ & NBR 12218/94 - item 5.10.2.1 \\
\hline & Qual o destino da água de descarga? & - & - & - & Item Informativo \\
\hline & $\begin{array}{l}\text { Os pontos de descarga de redes estão } \\
\text { devidamente protegidos? Verificar a situação das } \\
\text { caixas, tampas e registros. }\end{array}$ & - & $x$ & $x$ & Item sujeito à recomendação da Agência \\
\hline & Total de macromedidores instalados? & $x$ & $x$ & $x$ & Item Informativo \\
\hline & Frequência de aferição dos macromedidores? & - & - & - & Item Informativo \\
\hline & Percentual de micromedição? & $x$ & - & $x$ & Item Informativo \\
\hline & Idade média dos hidrômetros? & $x$ & - & - & Item Informativo \\
\hline & Há programa para troca de hidrômetros? & $x$ & - & - & Item Informativo \\
\hline & $\begin{array}{l}\text { Há programa específico para avaliação dos } \\
\text { hidrômetros de grande consumidores? }\end{array}$ & $x$ & - & - & Item Informativo \\
\hline \multirow{12}{*}{$\begin{array}{l}\text { Rede de } \\
\text { Distribuição }\end{array}$} & Existe cadastro técnico atualizado da rede? & $x$ & $x$ & $x$ & Item sujeito à recomendação da Agência \\
\hline & $\begin{array}{l}\text { Existem registros de manobras para manutenção } \\
\text { da rede? }\end{array}$ & - & - & $x$ & Item Informativo \\
\hline & Há programa de pesquisa de vazamentos? & $x$ & - & - & Item Informativo \\
\hline & $\begin{array}{l}\text { Ocorrem vazamentos frequentes na rede? } \\
\text { Verificar frequência e ocorrências operacionais. }\end{array}$ & - & $x$ & - & Item Informativo \\
\hline & Há manutenção preventiva em registros da rede? & $x$ & - & - & Item Informativo \\
\hline & Há programa de combate à fraudes? & $x$ & - & - & Item Informativo \\
\hline & Há ensaio de recebimento de novas redes? & $x$ & - & - & Item Informativo \\
\hline & $\begin{array}{l}\text { Descumprimento do padrão recomendado para o } \\
\text { parâmetro flúor na água tratada. }\end{array}$ & $x$ & $x$ & $x$ & Portaria no 635/GM/MS/76 - Quadro I \\
\hline & $\begin{array}{l}\text { Descumprir ou não monitorar os padrões de } \\
\text { potabilidade no sistema de distribuição estabelecidos } \\
\text { na Portaria do Ministério da Saúde vigente. }\end{array}$ & $x$ & $x$ & $x$ & Portaria do MS n 2.914/11 - Anexos I e XII \\
\hline & $\begin{array}{l}\text { Descumprimento do número mínimo de } \\
\text { amostras para controle da qualidade da água no } \\
\text { sistema de distribuição. }\end{array}$ & - & $x$ & $x$ & Portaria do MS n 2.914/11 - Anexos XII e XIII \\
\hline & $\begin{array}{l}\text { Descumprimento da frequência mínima de coleta } \\
\text { para análise dos parâmetros para controle da } \\
\text { qualidade da água no sistema de distribuição. }\end{array}$ & - & $x$ & $x$ & Portaria do MS n 2.914/11 - Anexos XII e XIII \\
\hline & $\begin{array}{l}\text { Não cumprimento da publicidade mensal nas } \\
\text { contas de água acerca dos resultados das } \\
\text { análises referentes aos parâmetros básicos de } \\
\text { qualidade da água. }\end{array}$ & $x$ & $x$ & $x$ & Decreto no 5.440/05 - Inciso I do Art. $5^{\circ}$ \\
\hline
\end{tabular}


Apêndice 1 - Continuação.

\begin{tabular}{|c|c|c|c|c|c|}
\hline \multirow{2}{*}{\multicolumn{2}{|c|}{ Item Fiscalizado }} & \multicolumn{3}{|c|}{ Agência Reguladora } & \multirow{2}{*}{ Enquadramento } \\
\hline & & ARES-PC J & ARIS & ARCE & \\
\hline $\begin{array}{l}\text { Abastecimento } \\
\text { alternativo }\end{array}$ & $\begin{array}{l}\text { Não cumprimento da publicidade de informações } \\
\text { mínimas sobre a água para consumo humano } \\
\text { entregue aos consumidores por meios } \\
\text { alternativos de abastecimento. }\end{array}$ & - & - & - & Decreto no 5.440/05 - Art. 90 \\
\hline Documentos & $\begin{array}{l}\text { Ausência ou não atendimento do Plano de } \\
\text { Emergência e Contingência. }\end{array}$ & - & - & - & Lei Federal n 11.445/07 - Inciso V do Art. $2^{\circ}$ \\
\hline
\end{tabular}

*Unidade passível de ser empregada para água bruta e tratada.

\section{Legenda:}

\begin{tabular}{|c|c|}
\hline & Não Conformidade \\
\hline$X$ & Item considerado pela agência reguladora em checklist e resoluções, na perspectiva deste estudo \\
\hline
\end{tabular}

